\title{
SORO DO LEITE EM SUBSTITUIÇÃO AO LEITE NA CRIA DE BEZERROS
}

\author{
Julio Viégas ${ }^{1}$ \\ Fernando Reimann Skonieski ${ }^{2}$ \\ Alexandre $\mathrm{Weber}^{3}$ \\ Adalgiza Pinto-Neto ${ }^{2}$ \\ Ronaldo Lopes Oliveira ${ }^{4}$ \\ Cláudio Vaz Di Mambro Ribeiro ${ }^{4}$ \\ Rogério Fôlha Bermudes ${ }^{5}$ \\ Maria de Fátima Leal Nörnberg ${ }^{6}$
}

VIÉGAS, J.; SKONIESKI, F. R.; WEBER, A.; PINTO-NETO, A.; OLIVEIRA, R. L.; RIBEIRO, C. V. D. M.; BERMUDES, R. F.; NÖRNBERG, M. de F. L. Soro de leite em substituição ao leite na cria de bezerros. Arq. Ciênc. Vet. Zool. UNIPAR, Umuarama, v. 20, n. 1, p. 9-13, jan./mar. 2017.

\begin{abstract}
RESUMO: O uso de leite na alimentação de bezerras representa o maior custo na fase de cria. Com o objetivo de avaliar a viabilidade técnica da utilização de diferentes quantidades de dieta líquida na alimentação de bezerros da Raça Holandês, utilizou-se 160 ou 240 litros de dieta líquida, durante um período de 53 dias (do quarto ao $56^{\circ}$ dia de vida) de aleitamento com diferentes níveis de inclusão de soro de leite em substituição ao leite integral $(0,10$ e $20 \%)$, em esquema fatorial $2 \times 3$ (160 ou 240 litros de dieta líquida e 0,10 ou 20\% de inclusão de soro do leite), conduzido no Laboratório de Bovinocultura Leiteira da Universidade Federal de Santa Maria. Os animais foram distribuídos inteiramente ao acaso em seis tratamentos, com quatro repetições por tratamento. Foram avaliados o consumo de matéria seca do concentrado (CMSC), da matéria seca total (CMST), ganho médio diário (GMD), conversão alimentar (CA), peso vivo final (PVF) e o comportamento dos animais. Para os níveis de soro do leite, ocorreu uma resposta quadrática $(\mathrm{p}<0,05)$ para o CMSC, CMST, GMD e CA. Os bezerros que receberam 160 litros de leite apresentaram maior $(\mathrm{p}<0,05)$ CMSC, porém pior CA. O CMST, o GMD e o PVF foram superiores $(\mathrm{p}<0,05)$ para os bezerros que consumiram 240 litros de leite durante o período experimental, com melhor CA para esse grupo de animais. Na análise do comportamento não foi determinada diferença significativa para os parâmetros avaliados ( $\mathrm{p}>0,05)$. PALAVRAS-CHAVE: Aleitamento. Bovinos de leite. Conversão alimentar. Ganho médio diário.
\end{abstract}

\section{USE OF WHEY IN SUBSTITUTION TO MILK IN HOLSTEIN CALVES}

\begin{abstract}
The use of milk in the calves feed represents the largest cost in the calf production system. The aim was to evaluate the technical feasibility of using different amounts of liquid diet in feeding of Holstein calves. It was used 160 or 240 liters of milk during 53 days (from the fourth to the 56th day of life) of feeding with different levels of milk serum included to whole milk $(0,10$ and $20 \%)$, in a factorial $2 \times 3$ model conducted at the Dairy Cattle Laboratory of the Federal University of Santa Maria. The animals were randomly assigned to six treatments with four replicates per treatment. The dry matter intake of concentrate (DMIC), of the total dry matter (TDM), average daily gain (ADG), feed conversion (FC), final body weight (FBW) and the behavior of animals. For milk serum levels, there was a quadratic response $(\mathrm{p}<0.05)$ for the DMIC, TDM, ADG and FC. DMIC and FC were higher $(\mathrm{p}<0.05)$ for calves received 160 liters of milk. The ADG, TDM and FBW were higher for calves that consumed 240 liters of milk during the experimental period, while $\mathrm{FC}$ was lower $(\mathrm{p}<0.05)$ for this group of calves. There was no difference in the behavior of calves for the evaluated parameters ( $p>0.05)$.
\end{abstract}

KEYWORDS: Average daily gain. Dairy cattle. Feeding. Feed conversion. Weight gain.

\section{SUERO DE LECHE EN SUSTITUCIÓN A LA LECHE EN CRÍA DE TERNEROS}

RESUMEN: El uso de leche en la alimentación de terneros representa el costo más grande en la fase de creación. Con el fin de evaluar la viabilidad técnica de utilizar diferentes cantidades de dieta líquida en la alimentación de terneros de la raza holandesa, se utilizaron 160 o 240 litros de dieta líquida por un período de 53 días (desde el cuarto hasta el día $56^{\circ}$ día de vida), alimentación con diferentes niveles de adición de suero de leche entera $(0,10$ y 20\%), en un estudio factorial 2x3 (160 0240 litros de dieta líquida y 0,10 o $20 \%$ de inclusión de suero de leche), llevado a cabo en el Laboratorio de Ganado Lechero de la Universidad Federal de Santa María. Los animales se distribuyeron completamente al azar en seis tratamientos con cuatro repeticiones por tratamiento. Se evaluó el consumo de materia seca del concentrado (CMSC), de la materia seca total (CMST), ganancia media diaria (GMD), conversión alimenticia (CA), el peso vivo final (PVF) y el comportamiento de

\footnotetext{
DOI: https://doi.org/10.25110/arqvet.v20i1.2017.6313

${ }^{1}$ Docente. Titular do Departamento de Zootecnia da Universidade Federal de Santa Maria - UFSM. e-mail: jviegas@smail.ufsm.br

${ }^{2}$ Docentes. Curso de Medicina Veterinária. Campus Realeza - UFFS.

${ }^{3}$ Programa de Pós-Graduação em Zootecnia da Universidade Federal de Santa Maria - UFSM.

${ }^{4}$ Docente. Associado do Departamento de Produção Animal da Universidade Federal da Bahia - UFBA.

${ }^{5}$ Docente. Departamento de Zootecnia da Universidade Federal de Pelotas - UFPEL.

${ }^{6}$ Docente. Tecnologia do Leite e derivados e de Tecnologia dos Produtos de Origem Animal do DTCA/UFSM.
} 
los animales. Para los niveles de suero de leche, hubo una respuesta cuadrática $(\mathrm{p}<0,05)$ para el CMSC, CMST, GMD y CA. Los terneros que recibieron 160 litros de la leche presentaron mayor $(\mathrm{p}<0,05) \mathrm{CMSC}$, sin embargo con peor CA. Las variables CMST, GMD y PVF fueran mayores $(\mathrm{p}<0,05)$ para los terneros que consumieron 240 litros de leche durante el período experimental, mientras con mejor CA para ese grupo de animales. En el análisis del comportamiento no ha sido determinada diferencia significativa para los parámetros evaluados $(\mathrm{p}>0,05)$.

PALABRAS CLAVE: Ganado lechero. Amamantamiento. Conversón alimenticia. Ganancia media diaria.

\section{Introdução}

O leite tem papel de destaque tanto na dieta da população como na economia do país. Pesquisas vêm sendo realizadas buscando alternativas que permitam maximizar os índices produtivos e a receita líquida obtida com a atividade de produção leiteira (IPARDES, 2009). O mesmo leite utilizado para consumo humano é também usado na alimentação de bezerros. Portanto, subprodutos como o soro do leite ou sucedâneos lácteos mais baratos do que o próprio leite, apresentam potencial para o uso na alimentação de bezerras, podendo resultar em benefícios para o produtor, como produção de bezerros/novilhas a custos mais baixos, maiores quantidades de leite para a venda e menores quantidades de soro do leite na indústria, geradores de poluição ambiental (FONTES et al., 2006).

O crescente consumo de produtos lácteos, principalmente em países emergentes como o Brasil, acarreta maior preocupação com relação ao destino dos efluentes industriais. Nesse caso, enquadra-se o soro do leite que, ao ser despejado no meio ambiente, provoca sérios problemas de poluição (BARBOSA et al., 2009; OLIVEIRA, et al., 2012). Constata-se que este tipo de poluição é grave, uma vez que a fabricação de queijos é obtida pelo volume total de leite empregado, sendo $85 \%$ na forma de soro. Sendo assim, cada quilo de queijo produzido, em média, resulta em $5,6 \mathrm{~kg}$ de soro de elevado potencial poluente (ALAIS, 1985; MELLO, 1989).

Evidentemente, existe dúvida em relação ao volume e qualidade da dieta líquida dispensada aos bezerros, sem que haja comprometimento do desenvolvimento do animal. Normalmente, em sistemas de desaleitamento precoce utilizados no Brasil empregam-se quantidades pequenas de leite, entre 160 e $200 \mathrm{~kg}$ por bezerro, com o desaleitamento sendo realizado, normalmente, entre a quinta e a oitava semana de vida.

Os elevados teores de minerais e lactose e baixo teor de gordura (fatores predisponentes a diarreias) são as principais restrições à utilização em grandes quantidades de soro do leite na alimentação de bezerros. O soro é um produto líquido e perecível, com grande variabilidade em composição, o que dificulta seu manejo e comercialização. No entanto, Germano (1991) cita que o soro, embora apresente menor valor energético que o leite (41,6\% do total de energia digestível), supre as necessidades protéicas dos bezerros. Tronco (1997) relata que as proteínas do soro do leite, do ponto de vista nutricional, são das mais valiosas encontradas na natureza, sendo formadas pelas frações de albumina do soro, alfa-lactoalbumina, beta-lactoglobulina, imunoglobulinas e proteose-peptona.

Objetivou-se com esse estudo avaliar alternativas de baixo custo para aleitamento de bezerros leiteiros da Raça Holandês, a viabilidade técnica e o comportamento desses animais, sob aleitamento com diferentes níveis de inclusão de soro do leite em substituição ao leite integral.

\section{Material e Métodos}

O trabalho foi conduzido no Laboratório de Bovinocultura Leiteira da Universidade Federal de Santa Maria (UFSM), situada na região fisiográfica da Depressão Central do Estado do Rio Grande do Sul, à altitude de 95 m, 29 43' de latitude sul e $53^{\circ} 42^{\prime}$ de longitude oeste. O clima da região é o subtropical úmido, conforme classificação de Köppen, com precipitação média anual de $1769 \mathrm{~mm}$, temperatura média anual de $19,2^{\circ} \mathrm{C}$, com média mínima de $9,3^{\circ} \mathrm{C}$ em julho e média máxima de $24,7^{\circ} \mathrm{C}$ em janeiro.

Utilizaram-se bezerros (machos e fêmeas) da Raça Holandês, conduzidos em piquete de cria, sobre campo nativo em abrigos individuais, sendo introduzidos no experimento a partir do quarto dia de vida, após três dias de período colostral, e desmamados aos 56 dias de idade. Os tratamentos consistiram no fornecimento de 160 ou 240 litros de dieta líquida, durante o período de 53 dias de aleitamento, com três níveis de inclusão de soro de leite em substituição ao leite integral. $\mathrm{O}$ volume de dieta líquida fornecido diariamente aos animais experimentais foi de quatro e seis litros do quarto ao $30^{\circ}$ dia, e de dois e três litros do $31^{\circ}$ ao $56^{\circ}$, nos tratamentos com fornecimento total de 160 e 240 litros (Tabela 1 ).

Tabela 1: Aleitamento durante 56 dias de vida, em bezerros da raça Holandesa, submetidos à dieta líquida de leite e diferentes porcentagens de soro.

\begin{tabular}{|c|c|c|c|c|c|c|c|c|}
\hline \multirow{4}{*}{$\begin{array}{c}\text { Porcentagem } \\
\text { de substituição } \\
\text { do leite pelo } \\
\text { soro }\end{array}$} & \multicolumn{8}{|c|}{ Quantidade de dieta líquida } \\
\hline & \multicolumn{4}{|c|}{160 litros } & \multicolumn{4}{|c|}{240 litros } \\
\hline & \multicolumn{2}{|c|}{$4^{\circ}$ ao $30^{\circ}$ dia } & \multicolumn{2}{|c|}{$31^{\circ}$ ao $56^{\circ}$ dia } & \multicolumn{2}{|c|}{$4^{\circ}$ ao $30^{\circ}$ dia } & \multicolumn{2}{|c|}{$31^{\circ}$ ao $56^{\circ}$ dia } \\
\hline & $\begin{array}{l}\text { Leite } \\
\text { (1/dia) }\end{array}$ & $\begin{array}{c}\text { Soro } \\
\text { (1/dia) }\end{array}$ & $\begin{array}{l}\text { Leite } \\
\text { (l/dia) }\end{array}$ & $\begin{array}{c}\text { Soro } \\
\text { (l/dia) }\end{array}$ & $\begin{array}{l}\text { Leite } \\
\text { (l/dia) }\end{array}$ & $\begin{array}{c}\text { Soro } \\
\text { (1/dia) }\end{array}$ & $\begin{array}{l}\text { Leite } \\
\text { (1/dia) }\end{array}$ & $\begin{array}{c}\text { Soro } \\
\text { (1/dia) }\end{array}$ \\
\hline 0 & 4 & 0 & 2 & 0 & 6 & 0 & 3 & 0 \\
\hline 10 & 3,6 & 0,4 & 1,8 & 0,2 & 5,4 & 0,6 & 2,7 & 0,3 \\
\hline 20 & 3,2 & 0,8 & 1,6 & 0,4 & 4,8 & 1,2 & 2,4 & 0,6 \\
\hline
\end{tabular}

A dieta líquida, de acordo com cada tratamento, foi fornecida duas vezes ao dia, em baldes, às 07:30 e 17 horas. O soro do leite foi originado da Escola Usina de Laticínios da
UFSM, coletado nas terças e sextas-feiras, e armazenado em tonéis de 50 litros em resfriador de leite de imersão, sem a adição de qualquer tipo de conservante. 
O leite fornecido aos bezerros era composto de 87,7 $\%$ de água, $12,3 \%$ de extrato seco total (EST) e 3,27\% de gordura, enquanto o soro do leite continha 92,9\% de água e $7,1 \%$ de EST $(0,9 \%$ de gordura, $4,8 \%$ de lactose, $0,8 \%$ de minerais e $0,6 \%$ de proteína). Adicionalmente, a água foi fornecida ad libitum, em baldes e ao abrigo do sol.

A partir do oitavo dia pela manhã iniciou-se o fornecimento de concentrado, considerando $10 \%$ de sobras avaliadas no dia posterior ao fornecimento, com a finalidade de não ocasionar restrição ou desperdício, cuja composição era de grão de milho moído (57,6 \%), farelo de soja (37,9 \%), grão de sorgo moído (3,5\%), sal comum $(0,5 \%)$ e calcário calcítico $(0,5 \%)$, ajustada segundo os requerimentos nutricionais do NRC - Gado de leite (2001), contendo 86,9\% de matéria seca (MS), 19,9\% de proteína bruta (PB), 15,3\% de fibra em detergente neutro (FDN) e 73,8\% de nutrientes digestíveis totais (NDT).

O consumo de concentrado foi avaliado diariamente por meio dos controles de oferta e sobras, sendo as mensurações realizadas em balança com precisão de um grama, corrigido para consumo de concentrado na base seca. Foram avaliados ainda o consumo de MS da dieta líquida e o consumo de MS total (MS líquida + MS concentrado).

O ganho de peso dos animais foi calculado pela aferição do peso vivo ao início e término de cada etapa experimental $\left(4^{\circ}\right.$ ao $30^{\circ}$ dia e $31^{\circ}$ ao $56^{\circ}$ dia), em balança digital com precisão de $10 \mathrm{~g}$, após 12 horas de regime hídrico. A conversão alimentar foi calculada pela razão entre consumo de MS total e ganho de peso no período.

O comportamento dos animais experimentais foi avaliado durante três dias consecutivos, no período das 06:30 às 18:30 horas, onde seis observadores, em sistema de revezamento, anotaram a cada cinco minutos as seguintes atividades realizadas pelos bezerros: pastejando, ruminando em pé, ruminando deitado, ócio em pé, ócio deitado, atividades lúdicas, consumindo concentrado e consumindo água (CARLOTTO et al., 2007). Essa avaliação foi realizada no período em que os animais recebiam $100 \%$ da dieta líquida.

Utilizou-se o delineamento inteiramente casualizado, com os tratamentos distribuídos em um fatorial $2 \times 3$, sendo dois níveis de dieta líquida (160 e 240 litros) e três níveis de substituição do leite por soro do leite (0, 10 e 20\%), perfazendo seis tratamentos com quatro repetições (animais). Foi realizada análise de variância e comparação de médias por meio do Teste de Tukey, considerando ao nível de 5\% de probabilidade, utilizando-se o pacote estatístico SAS (2001). A data de entrada dos animais no experimento e o peso vivo ao nascer foram utilizados como covariáveis no modelo estatístico.

\section{Resultados e Discussão}

Não houve interação entre as diferentes percentagens de soro do leite e as quantidades de dieta líquida $(\mathrm{p}>0,05)$. Dessa forma, os dados foram analisados pelos seus efeitos principais, não apresentando efeito das covariáveis (peso inicial e final) analisadas sobre os parâmetros zootécnicos e comportamentais avaliados $(\mathrm{p}>0,05)$.

O menor consumo de dieta líquida (160 litros) favoreceu o consumo de concentrado pelos bezerros $(\mathrm{p}<0,05$ - Tabela 2), semelhante aos dados citados por Jasper e Weary
(2002). A redução do custo da alimentação de bezerros está associada com a redução do consumo de dieta líquida (leite) que poderá ser utilizado para venda pelo produtor rural, desde que não comprometa o desempenho dos animais. Esse aspecto é importante na medida em que determinará o maior ou menor aporte de energia e a regulação da ingestão da dieta sólida (FONTES et al., 2006). Maior consumo de concentrado está associado ao desenvolvimento de papilas ruminais permitindo rápida passagem do bezerro de pré-ruminante para ruminante efetivo (LEEK, 2006).

Tabela 2: Parâmetros avaliados em bezerros da raça Holandesa até os 56 dias de idade, submetidos a diferentes quantidades de dieta líquida

\begin{tabular}{lcc}
\hline \multicolumn{1}{c}{ Parâmetros avaliados } & $\mathbf{1 6 0}$ litros & $\mathbf{2 4 0}$ litros \\
\hline $\begin{array}{l}\text { Consumo de concentrado na base } \\
\text { seca }(\mathrm{kg})\end{array}$ & $15,70^{\mathrm{a}}$ & $13,28^{\mathrm{b}}$ \\
$\begin{array}{l}\text { Consumo de MS dieta líquida } \\
(\mathrm{kg})\end{array}$ & $18,38^{\mathrm{b}}$ & $27,31^{\mathrm{a}}$ \\
Consumo de MS total $(\mathrm{kg})$ & $34,08^{\mathrm{b}}$ & $40,59^{\mathrm{a}}$ \\
Ganho de peso (kg) & $13,60^{\mathrm{b}}$ & $21,50^{\mathrm{a}}$ \\
Ganho médio diário (kg) & $0,24^{\mathrm{b}}$ & $0,38^{\mathrm{a}}$ \\
Conversão alimentar & $2,51^{\mathrm{a}}$ & $1,89^{\mathrm{b}}$ \\
\hline
\end{tabular}

a,b Médias seguidas de letras diferentes, na mesma linha, diferem $(\mathrm{p}<0,05)$.

O maior consumo de dieta líquida, observado nos animais alimentados com 240 litros, diminuiu o consumo de concentrado, no entanto, proporcionou maior consumo de MS total, sendo fundamental para maior aporte de nutrientes e maior ganho de peso em todo o período de avaliação $(p<0,05$ - Tabela 2). Além disso, a menor conversão alimentar foi obtida quando os animais ingeriram maior quantidade de dieta líquida, evidenciando a menor qualidade do concentrado em relação a dieta líquida $(p<0,05)$. Segundo Guimarães et al. (2012), a melhor eficiência na conversão é resultado de oferta de energia e nutrientes acima das exigências de mantença.

Tabela 3: Parâmetros avaliados em bezerros da raça Holandesa até os 56 dias de idade, submetidos a diferentes porcentagens de soro de leite administrados a dieta líquida.

\begin{tabular}{lccc}
\hline \multicolumn{1}{c}{ Parâmetros avaliados } & \multicolumn{4}{c}{$\begin{array}{c}\text { Porcentagem de soro } \\
\text { ofertado na dieta }\end{array}$} \\
\hline & $\mathbf{0}$ & $\mathbf{1 0}$ & $\mathbf{2 0}$ \\
Consumo de concentrado (kg) & $14,99^{\mathrm{b}}$ & $19,15^{\mathrm{a}}$ & $11,97^{\mathrm{c}}$ \\
Consumo de MS dieta líquida & $24,60^{\mathrm{a}}$ & $23,82^{\mathrm{ab}}$ & $22,52^{\mathrm{b}}$ \\
$(\mathrm{kg})$ & $39,59^{\mathrm{b}}$ & $42,97^{\mathrm{a}}$ & $34,49^{\mathrm{c}}$ \\
Consumo de MS total (kg) & $18,88^{\mathrm{ab}}$ & $23,00^{\mathrm{a}}$ & $16,58^{\mathrm{b}}$ \\
Ganho de peso (kg) & $0,34^{\mathrm{ab}}$ & $0,41^{\mathrm{a}}$ & $0,30^{\mathrm{b}}$ \\
Ganho médio diário (kg) & $2,10^{\mathrm{ab}}$ & $1,87^{\mathrm{b}}$ & $2,08^{\mathrm{ab}}$
\end{tabular}

a,b Médias seguidas de letras diferentes, na mesma linha, diferem $(\mathrm{p}<0,05)$.

O soro de leite, por conter proteínas de elevado valor 
nutricional, é considerado uma alternativa viável na alimentação de bezerros como substituto do leite e, portanto, fator importante na diminuição do custo de cria desses animais (FONTES et al., 2006; LIMA et al., 2012). A inclusão de 10\% de soro do leite na dieta dos bezerros experimentais proporcionou maior consumo de concentrado $(p<0,05)$, o que poderia antecipar o desaleitamento. Além disso, esses animais consumiram maior quantidade de MS total, com maior ganho de peso no período e melhor conversão alimentar $(\mathrm{p}<0,05$ Tabela 3).

De forma contrária, a inclusão de $20 \%$ de soro a dieta dos bezerros estudados não foi satisfatória, uma vez que esses animais apresentaram o menor consumo de concentrado e MS total $(\mathrm{p}<0,05)$, possivelmente levando à consequências negativas sobre seu desempenho (Tabela 3). Cabe salientar que o menor consumo de MS na dieta líquida, para os animais suplementados com soro de leite, deve-se a menor quantidade de sólidos totais nesse material (Tabela 3).

A queda no consumo de MS total e de concentrado, após $10 \%$ de inclusão de soro de leite, foi observada em bezerros de zero a seis semanas, que apresentaram maior consumo com o emprego de até $10 \%$ de soro do leite, e posterior diminuição até 30\% de soro na dieta (MORRIL et al., 1974). Especula-se que a queda no consumo de MS com inclusões de soro de leite acima de $10 \%$ ocasiona diminuição da palatabilidade da dieta líquida, podendo também ocasionar desconforto pós-ingestivo, como elevada acidez estomacal e diarreia (CARLOTTO et al., 2007). A diminuição do consumo à medida que aumentou a percentagem de soro do leite na dieta líquida também foi observada por Anderson et al. (1974), ao relatarem significativa redução do consumo de feno e concentrado $(0,700$ a 1 e $1 \mathrm{~kg} / \mathrm{dia}$, respectivamente) para cada quilo de soro, do leite em pó consumido por bezerros da raça Holandesa.

A quantidade de dieta líquida e as diferentes porcentagem de soro de leite na dieta ingerida não interferiram no comportamento dos bezerros experimentais, em nenhuma das atividades avaliadas ( $>00,05$ - Tabelas 4 e 5). Considerando os valores médios dos tratamentos, observou-se que o comportamento mais comum dos bezerros foi o ócio $(60 \%$ do tempo avaliado nesta condição), sendo $46 \%$ das observações em ócio deitado e 14\% em ócio de pé. Os animais permaneceram $17,5 \%$ do tempo de avaliação em pastejo, sendo realizado com maior frequência nas primeiras horas da manhã, ao redor do meio dia e ao entardecer. A ruminação respondeu por $10,5 \%$ do tempo de avaliação, ocorrendo com maior frequência no meio da manhã e da tarde, sendo que os animais começaram a ruminar em torno dos 30 dias de idade.

Tabela 4: Parâmetros comportamentais de bezerros da raça Holandesa até os 56 dias de idade, submetidos à diferentes quantidades de dieta líquida. 240 litros

\begin{tabular}{|c|c|c|c|c|c|}
\hline \multirow[b]{2}{*}{ Posição } & \multirow[b]{2}{*}{ Atividade } & \multicolumn{2}{|c|}{160 litros } & \multicolumn{2}{|c|}{240 litros } \\
\hline & & $\begin{array}{c}\text { Horas de } \\
\text { observação }\end{array}$ & $\%$ & $\begin{array}{c}\text { Horas de } \\
\text { observação }\end{array}$ & $\%$ \\
\hline \multirow{2}{*}{ Deitado } & Ócio & 5,54 & 46,2 & 5,50 & 45,8 \\
\hline & Ruminando & 1,19 & 9,92 & 0,87 & 7,25 \\
\hline \multirow{6}{*}{ Em pé } & Ócio & 1,58 & 13,2 & 1,78 & 14,8 \\
\hline & Ruminando & 0,24 & 2,0 & 0,22 & 1,83 \\
\hline & Pastejando & 1,97 & 16,4 & 2,23 & 18,6 \\
\hline & At. Lúdicas & 0,86 & 7,16 & 1,06 & 8,83 \\
\hline & Ração & 0,42 & 3,50 & 0,14 & 1,17 \\
\hline & Água & 0,20 & 1,67 & 0,20 & 1,67 \\
\hline
\end{tabular}

Tabela 5: Parâmetros comportamentais de bezerros da raça Holandesa até os 56 dias de idade, submetidos à diferentes porcentagens de soro de leite administrados a dieta líquida.

\begin{tabular}{cccccccc}
\hline & & \multicolumn{5}{c}{ Porcentagem de soro ofertado na dieta } \\
\cline { 3 - 8 } Posição & Atividade & \multicolumn{2}{c}{$\mathbf{0 \%}$} & \multicolumn{3}{c}{$\mathbf{1 0 \%}$} & \multicolumn{3}{c}{$\mathbf{2 0 \%}$} \\
\cline { 3 - 8 } & & $\begin{array}{c}\text { Horas de } \\
\text { observação }\end{array}$ & $\mathbf{( \% )}$ & $\begin{array}{c}\text { Horas de } \\
\text { observação }\end{array}$ & $\mathbf{( \% )}$ & $\begin{array}{c}\text { Horas de } \\
\text { observação }\end{array}$ & (\%) \\
\hline \multirow{2}{*}{ Deitado } & Ócio & 5,69 & 47,4 & 5,16 & 43,0 & 5,71 & 47,6 \\
& Ruminando & 0,81 & 6,75 & 1,42 & 11,8 & 0,85 & 7,08 \\
& Ócio & 1,76 & 14,6 & 1,35 & 11,2 & 1,92 & 16,0 \\
& Ruminando & 0,23 & 1,92 & 0,33 & 2,75 & 0,17 & 1,42 \\
\multirow{3}{*}{ Em pé } & Pastejando & 2,24 & 18,6 & 2,01 & 16,7 & 2,06 & 17,2 \\
& At. Lúdicas & 0,93 & 7,75 & 1,15 & 9,58 & 0,79 & 6,58 \\
& Ração & 0,16 & 1,33 & 0,42 & 3,50 & 0,26 & 2,17 \\
& Água & 0,18 & 1,50 & 0,16 & 1,34 & 0,24 & 2,0 \\
\hline
\end{tabular}




\section{Conclusão}

Nas condições desse estudo, a substituição do leite por soro do leite na dieta líquida deve ser no máximo de $10 \%$, durante o aleitamento de bezerros da Raça Holandês, até os 56 dias de vida. O melhor desempenho dos animais foi obtido com o fornecimento de 240 litros de dieta líquida durante o período experimental.

\section{Referências}

ALAIS, C. Ciência de la leche: Princípios de tecnica lechera. 4ed. Barcelona: Reverte, 1995. 873p.

ANDERSON, M. J. et al. Feeding liquid whey to dairy cattle. Journal Dairy Science, v. 57, p. 1206, 1974

BARBOSA, C. S. et al. Aspectos e impactos ambientais em um lactício de pequeno porte. Revista do Instituto Laticínios "Cândido Tostes", v. 64, n. 366, p. 28-35, 2009.

CARLOTTO, S. B. et al. Performance and behavior of dairy calves fed diets containing milk and citric flavor agentes. Ciência e Agrotecnologia, v. 31, n. 3, p.889-895, 2007.

FONTES, F. A. P. V. Desempenho de bezerros alimentados com dietas líquidas à base de leite integral ou soro de leite. Arquivo Brasileiro de Medicina Veterinária e Zootecnia, v. 58, p. $212-219,2006$.

GERMANO, J. L. Utilização de substitutos do leite a base de soja e soro de queijo na alimentação de bezerros. Lavras, 1991. 54p. Dissertação (Mestrado em Zootecnia) Escola Superior de Agricultura de Lavras.

GUIMARÃES, T. P. et al. Conceitos e exigências de energia para bovinos de corte. Revista Brasileira de Agrociência, v. 18 , n. 1, p. 54-67, 2012.

\section{INSTITUTO PARANAENSE DE DESENVOLVIMENTO ECONÔMICO E SOCIAL. Caracterização socioeconômica da atividade leiteira no Paraná: sumário executivo. Curitiba: IPARDES. 2009.}

JASPER, J.; WEARY, D. M. Effects of ad libitum milk intake on dairy calves. Journal Dairy Science, v.85, p.3054, 2002

LEEK, B. F. Digestão no estômago do ruminante. In: REECE, W.O. Dukes: Fisiologia dos animais domésticos. 12ed. Rio de Janeiro: Guanabara Koogan, 2006. p.404-437.

LIMA, R. N. et al. Desempenho de bezerros aleitados com soro de queijo em associação ao colostro. Revista Agropecuária Brasileira, v. 47, n. 8, p. 1174-1180, 2012.

MELLO, E. M. Obtenção e caracterização de concentrado protéico de soro de queijo por ultrafiltraçao. Campinas, 1989. 108p. Dissertação (Mestrado em Tecnologia de Alimentos), Universidade de Campinas. starter palatability. Journal Dairy Science, v. 57, p. 430434, 1974.

NRC - National Research Council. Nutrient requirements of dairy cattle. 7 th. Ed. National Academy Press: Washington D.C., 2001. 405 p.

OLIVEIRA, D. F.; BRAVO, C. E. C.; TONIAL, I. B. Soro de leite: um subproduto valioso. Revista do Instituto de Laticínios Cândido Tostes, v. 67, n. 385, 2012.

SAS - Institute. Statistical analysis system user's guide. Version 8.02. Cary: Statistical Analysis System Institute, 2001.

TRONCO, M. V. Manual para inspeção da qualidade do leite. Ed. da UFSM: Santa Maria, 1997.

Recebido em: 20.11.2016 Aceito em: 14.02.2017

MORRIL, J. L.; DAYTON, A. D. Effect of whey on calf 